\title{
Visualizing the Spatial and Temporal Dynamics of Ozone Concentration Data
}

\author{
H.F. Mayer and W. Haas
}

JOANNEUM RESEARCH, Institute of Information Systems

Steyrergasse 17, A-8010 Graz, Austria

e-mail: \{mayer,haas\}@pbox.joanneum.ac.at

\section{J. Züger and W. Loibl}

Austrian Research Centre Seibersdorf

A-2444 Seibersdorf, Austria

e-mail: $\{z u e g e r, l o i b l\} @ z d v a x a . a r c s . a c . a t$

\begin{abstract}
In Austria the ozone concentrations are measured by a network of more than 130 monitoring stations. In order to perceive the temporal and spatial dynamics of such concentration data, it is necessary to develop special visualization techniques. This paper describes the various steps in preparing the data and providing results on graphic workstations, on video tapes and online through the World-Wide Web.
\end{abstract}

\section{Keywords}

Environmental research and planning, ozone, visualization, World-Wide Web

\section{INTRODUCTION}

Research into the origin, distribution and effects of ozone is internationally regarded as one of the biggest challenges in the area of environmental research and planning. This particularly applies to the high levels of ozone in the tropospheric boundary layer in summer which are a major environmental concern in Austria. A network of more than 130 monitoring stations has been established throughout the country to measure and analyze ozone concentrations. This network is operated by the Austrian provinces and the Federal Environment Agency. In the 
past few years the Austrian Research Centre Seibersdorf (Loibl, 1993) developed a model to estimate the spatial distribution and diurnal variation of ozone referring to the point data measured every half an hour at the monitoring stations. By using a digital elevation model and the monitoring data, the ozone concentration of areas between monitoring sites can be calculated.

The results of this spatial interpolation procedure are ozone concentration maps for every half an hour of a day. A fundamental disadvantage of such static visualizations is that the temporal sequence and dynamics of the processes behind it can only be grasped incompletely. To clearly depict the dynamics of ozone development for both the analyzing reseacher and the interested public, we applied interactive and dynamic visualization techniques. The results of this piece of research are documented on video and will be discussed in this paper.

\section{OZONE CONCENTRATION AS A FUNCTION OF TIME AND ALTITUDE}

Monitoring data are only representative for the pollution levels at the very monitoring sites. However, information about the spatial distribution of ozone levels is necessary to assess the impact of pollution on human health and ecosystems. Therefore, the ozone levels in the areas between the monitoring stations have to be calculated.

Ozone is produced from precursor air pollutants under sunlight. The rate of formation is dependent on meteorological and chemical conditions. In areas with anthropogenic pollution there is a build-up of ozone with increasing solar radiation during the day, and a reduction of ozone at night. In higher altitudes, ozone levels are higher first and remain much the same throughout the day.

The diurnal variation of ozone is bell-shaped in valleys and more uniform with higher altitudes. So in regions with complex terrain and pronounced topographical variation - as it is the case in Austria - ozone levels will be very different even within small areas.

The Austrian Research Centre Seibersdorf (Züger, 1994) has developed a method for the spatial interpolation of ozone monitoring data. This method is based on a mathematical function which describes the altitude and diurnal variability of ozone. Using a digital elevation model and the monitoring data, the ozone concentrations can be calculated for areas between monitoring sites. After the preprocessing of this data the concentrations are available as halfhour mean values on a rectangular grid with a resolution of $2500 \times 2500$ meters.

\section{STATIC VISUALIZATION}

Before the temporal animation, which is produced by single frames following one another, the preprocessed data have to be mapped onto suitable geometric objects (Brodlie, 1992). These objects can be viewed on various output media (monitor, paper, video), using different rendering methods.

In our case the relationship between ozone levels and relative altitude was to be documented. For this purpose we generate a three-dimensional grid of a digital elevation model of Austria in the resolution of $2500 \times 2500$ meters. Each grid point is colored according to the concentration at this position. The color in the areas between the grid points is interpolated by the rendering process using Gouraud shading (Foley et al, 1990). 


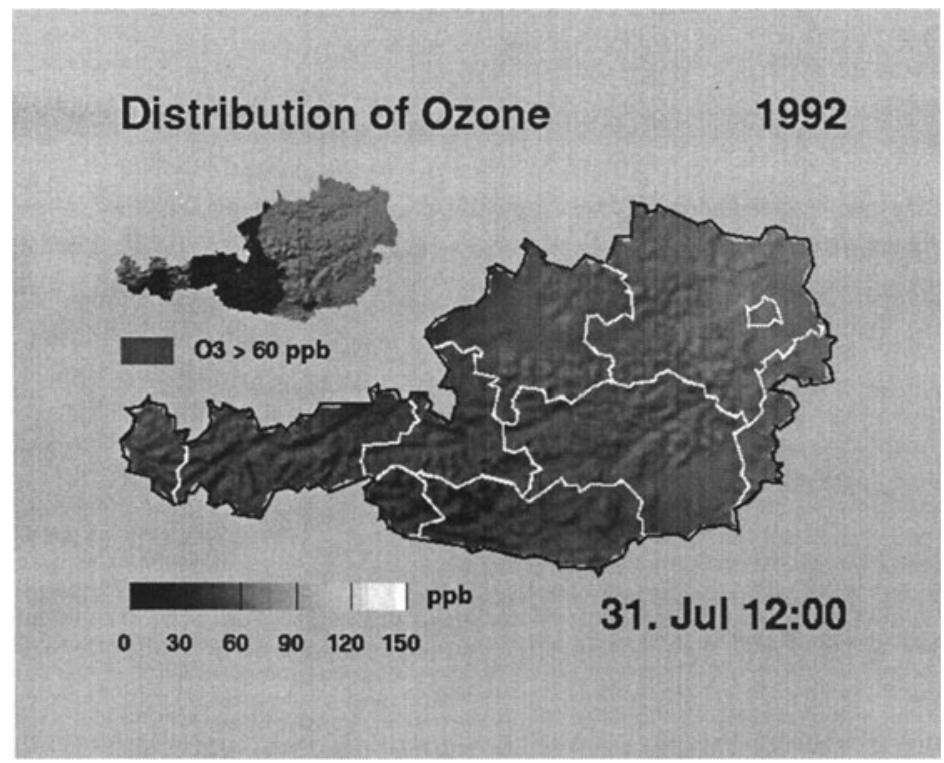

Figure 1 Ozone concentrations on 31 July 1992, 12:00 a.m.

The selection of a suitable colormap for the coding of the data is of crucial significance. There is some literature on this topic (Hopgood, 1991 and Murch, 1986), however, the results are individually different. For that reason we carried out a survey with approximately 50 persons who were asked to sort some color cards according to their subjective perception of the severity of pollution. The results of this survey were analyzed with statistical methods (cluster analysis) and delivered two representative color maps which were incorporated into the map used for the actual visualization.

The elevation model is overlayed with polylines representing the federal and provincal borders to help the viewer get his bearings.

The mapping of the data onto three-dimensional geometries allows studying from different viewpoints, local zooming and flying over regions in an interactive visualization environment (e.g. graphic workstations). The elevation model is illuminated from north-west to make the height influence visible from all perspectives.

\section{LAYOUT OF CONCENTRATION MAPS}

After selection of the principal visualization method, the overall graphical representation has to be constructed. The goal is to visualize all information in a highly expressive way. However, caution is needed for the combined visualization of several scalar or vectorial data in order not to confuse the observer. This principle particularly holds for animations where the observation time is usually fixed. 
Considering all these findings, we selected the following layout for the visualization (see Figure 1):

- The ozone concentrations of Austria are shown in detail on a nearly screen-sized map viewed from above.

- Two states of pollution colored green and red are indicated on a small map of Austria, thus specifying which areas have got a concentration level below or above a half-hour mean value of 60 parts per billion. This value is an Austrian guideline for human health protection.

- On the bottom right there is the corresponding date and time of the visualized data set.

- On the bottom left the color map for the coding of the big map is displayed.

Other variants of visualization, e.g. perspective view of the map from the side, proved to be interesting. For the final version, however, we chose the simple view from above to ensure a high degree of information and to facilitate analysis with a kind of visualization the observers are used to.

\section{DYNAMIC VISUALIZATION}

After choosing the layout and visualization methods for a single map, the dynamic visualization can be built by concatenating a sequence of single frames of successive data sets. For that reason the concentration data have to be interpolated for every moment between two given half-hour data sets. We use a simple linear interpolation for this task. Higher order interpolation methods proved to be not necessary for this kind of problem.

1250 frames are needed to play back one day of an ozone episode speeded up in 50 seconds. As high-performance graphics workstations are not yet capable of producing such an animation in real-time, each frame has to be calculated by its own and recorded to a digital video disk recorder. As soon as all frames are recorded the animation can be viewed in realtime and copied to the usual magnetic tapes.

Also the small bandwidth of video has to be considered when producing animation on video. In particular there are problems with fine details (e.g. thin lines) and with a limited color spectrum.

A script was developed to integrate the visualization together with a short description of the spatial interpolation method into a self-describing and entertaining video. This video was presented to a broad audience within the framework of a fair for environmental technology.

\section{ONLINE VISUALIZATION IN THE WORLD-WIDE WEB}

Apart from producing a video where the information is fixed to a chosen ozone episode, we developed a concept to provide access to online information. The emerging World-Wide Web (Berners-Lee, 1992) offers an open environment for implementing such multi-media applications and to distribute the information to everyone on the Internet.

Animations are provided in the form of MPEG (ISO 11172, 1993) video streams, an international standard for compressed digital video. These streams can be decoded by software and viewed on PCs and workstations. For playback in realtime, however, a hardware MPEG decoder is necessary. Apart from animation it is possible to point and click at the monitoring stations on a map to obtain the latest concentration data. 
A prototype of this application can be reached by accessing the address (URL) http://iis.joanneum.ac.at/ozonanim.

\section{CONCLUSION}

The spatial and temporal dynamics of ozone concentration data can only be visualized by using interactive and dynamic visualization techniques. The results of such visualizations can be analyzed on graphic workstations, presented to a broad audience on video or made available online using the World-Wide Web. In all cases, these techniques have proven to be very helpful, either to introduce to the problem in short time or to help grasp the problem and possible solutions.

\section{ACKNOWLEDGEMENTS}

The work described in this paper was done in cooperation of JOANNEUM RESEARCH and the Austrian Research Centre Seibersdorf. It was supported by the Austrian Federal Ministry of Science and Research. We would like to thank the Federal Environment Agency of Austria who provided the ozone data.

\section{REFERENCES}

Berners-Lee T.J, Cailliau R., Groff J.-F. and Pollermann B., "World-Wide Web: An Information Infrastructure of High-Energy Physics", Proceedings of Software Engineering, Artificial Intelligence and Expert Systems of High Energy and Nuclear Physics, La Londe-les-Maures, France, 1992.

Brodlie et al. (Eds.), Scientific Visualization, Springer, 1992.

Foley J.D., van Dam A., Feiner S.K. and Hughes J.F., Computer Graphics - Principles and Practice, Addison-Wesley, 1990.

Hopgood F.R.A., "Using Color in Computer Graphics", AGOCG Technical Report 4, 1991.

ISO/IEC International Standard 11172, Information Technology - Coding of moving pictures and associated audio for digital storage media up to about $1.5 \mathrm{Mbit} / \mathrm{s}, 1993$.

Loibl W., Züger J., Kopsca A., "Flächenhafte Ozonverteilung in Österreich für ausgewählte Ozonepisoden 1991", in German, Report of the Federal Environment Agency Austria, UBA-93-071, 1993.

Murch G.M., "Human Factors of Colour Displays", Advances in Computer Graphics, Springer, 1986.

Züger J., "Erstellung von Datensätzen zur Animation des Ozonkonzentrationsverlaufs von Ozonepisoden 1992", in German, Report of the Austrian Research Centre Seibersdorf, OEFZS-A-3255, 1994. 


\section{BIOGRAPHY}

Harald F. Mayer graduated in technical mathematics from Graz University of Technology in 1989 with a degree dissertation in the field of digital image processing. Since 1990 he has been working for the company of JOANNEUM RESEARCH where he focuses on research projects dealing with scientific visualization and computer graphics. His activity centers on the visualization of results from Finite Element simulations (pollution transport), Computational Fluid Dynamics (turbulent flow in engines) and ozone concentration data.

Werner Haas graduated in technical physics from Graz University of Technology in 1973. Afterwards he worked at the Institute for Hydraulics at the Graz University of Technology on a computer-aided measurement system. Subsequently, he was employed by a software house where he carried out extensive developments on Finite Elements models and methods applied to hydraulics and mechanics. Since 1988 he has been working for the company of JOANNEUM RESEARCH where he is now the director of the Institute of Information Systems.

Johann Züger has been working on air- and groundwater pollution dispersion models since several years. During last year he was dealing with photochemical models to simulate ozone built up deputy on precursors and additionally he is working on animated spatial results of the maintained models.

Wolfgang Loibl was the leader of several projects dealing with the modeling of spatial patterns of diurnal ozone variation in alpine regions depending on day-time and altitude. Further projects were spatially disaggregated emission inventories (NMVOC, $\mathrm{NO}_{\mathrm{x}}$, Methane, etc.) using land cover patterns to model the emissions density with spatial resolution and estimations of critical loads and levels of this and other pollutants depending on land cover. 